\title{
Aritmética e geometria nos anos iniciais: o passado sempre presente
}

\author{
Arithmetic and geometry in elementary school: the past always present
}

\section{Resumo}

O texto analisa as mudanças na Matemática ensinada, no que hoje se denomina Ensino Fundamental I, e expõe resultados de investigações que vêm sendo realizadas por um grupo nacional de pesquisadores, voltados para a educação matemática em perspectiva histórica. Adota como referencial teórico-metodológico estudos voltados para a História Cultural a partir de autores como Roger Chartier. $\bigcirc$ estudo ainda considera as pesquisas no âmbito da história das disciplinas escolares, levando em considerações as análises empreendidas por André Chervel. Como base empírica da pesquisa, são considerados documentos como programas de ensino, livros didáticos, manuais pedagógicos. Os resultados da análise histórica sobre a Aritmética e Geometria presentes nos ensinos dos anos iniciais permitem problematizar e ressaltar a importância da história da educação matemática na formação de professores.

Palavras-chave: Educação matemática. Aritmética. Geometria.
Maria Célia Leme da Silva

Wagner Rodrigues Valente Universidade Federal de São Paulo

\section{Abstract}

The paper analyzes the changes in mathematics taught in what is known today as elementary school, and presents the results of investigations that have been carried out by a national group of researchers focused on mathematics education in historical perspective. Adopts as a theoretical and methodological studies on the Cultural History from authors such as Roger Chartier. The study also considers the research into the history of school subjects, taking into consideration the analyzes undertaken by André Chervel. As empirical research, documents are considered as curriculum, textbooks, teaching manuals. The results of the historical analysis of the Arithmetic and Geometry emphasize the importance of the history of mathematics education in teacher training.

Keywords: Mathematics education. Arithmetic. Geometry. 


\section{Considerações iniciais}

Este texto tem por objetivo contribuir com as reflexões acerca da educação matemática nos anos iniciais escolares. $\bigcirc$ trabalho remete a uma discussão aprofundada sobre as mudanças da Matemática ensinada nos anos iniciais escolares. $\bigcirc$ estudo das transformações dos saberes escolares, ao longo do tempo, é objeto da história das disciplinas, campo relativamente novo. Assim sendo, o texto analisa as mudanças na Matemática ensinada, no que, hoje, se denomina Ensino Fundamental I, e expõe resultados de investigações que vêm sendo realizadas por um grupo nacional de pesquisadores, voltados para a educação matemática em perspectiva histórica. Os resultados obtidos dessa análise, de outra parte, desde logo, são confrontados com a seguinte questão: A que serve, para o professor que ensina matemática, os resultados da produção científica sobre história da educação matemática? Para responder a essa questão, é frequente o uso de uma já velha retórica, construída pelos historiadores, mencionada por Roger Chartier (1997), e apropriada por muitos pesquisadores da história da educação matemática. Diz ela: $\bigcirc$ professor, conhecendo a história da educação matemática, compreenderia o estágio atual de seu ofício. Ou, de modo mais simples: a história da educação matemática é importante para entender os problemas do presente... Tais assertivas não deixam de ser um canto da sereia, numa área onde a necessidade de resolver problemas imediatos, tende a absorver, tão somente, propostas de cunho extremamente pragmático. Via de regra têm validade os projetos que apontem, sem mediações, para a melhoria do ensino e aprendizagem da Matemática escolar. A eles, o crédito de relevante é dado sem delongas. Daí, a justificativa retórica de que a história da educação matemática serviria para a compreensão dos problemas presentes... Mas, como diz Chartier, isso não se dá dessa forma. Não há uma transmissão direta, linear, do passado para o presente. A história não é regida por leis de causa e consequência. Então, para que serve a história da educação matemática ao professor que ensina matemática? Qual seria a importância de discorrer e expor resultados de pesquisas sobre as mudanças da matemática escolar presente nos anos iniciais escolares, desde priscas eras?

Junta-se aos resultados das pesquisas sobre história da educação uma explicação menos pragmática, mais elaborada e de difícil instrumentalização. 
Otrabalho do historiador da educação matemática refere-se àquele de construção de ultrapassagens de relações ingênuas, míticas, românticas e memorialísticas sobre as práticas do ensino de matemática realizadas noutros tempos. A utilidade de sua produção - cujo resultado é uma história da educação matemática - é a de considerar que um professor que ensine matemática que mantenha uma relação a-histórica com os seus antepassados profissionais possa, com a apropriação dessa história, se relacionar de modo menos fantasioso e mais científico com esse passado. Isso deveria contribuir para uma reflexão e atuação sobre as suas práticas cotidianas de forma diferenciada, que passam a ser realizadas de modo mais consistente.

As considerações expostas acima, sobre a relevância da história da educação matemática para o professor que ensina esse saber, evidentemente, constituem uma aposta no devir, cujo cerne ancora-se no princípio de que mais conhecimento implica melhores práticas de ensino: a alteração da relação que o professor de matemática tem com o passado profissional de seu ofício leva, assim, a uma mudança de qualidade de suas práticas na realidade presente.

Ao tomar conhecimento da história da educação matemática, o professor de matemática beneficia-se daquilo que é o núcleo do trabalho do historiador, que, no dizer de Chartier, inscreve-se nas profecias sobre o futuro, por mais estranho que isso possa parecer:

Para situar melhor as grandezas e misérias das transformações do presente, talvez seja útil apelar para a única competência de que podem vangloriarem-se os historiadores. Têm sido sempre lamentáveis profetas, mas, às vezes, ao recordar que o presente está cheio de passados sedimentados ou emaranhados, puderam contribuir com um diagnóstico mais lúcido das novidades que seduziram ou espantaram os seus contemporâneos. (CHARTIER, 2008, p. 15, tradução nossa).

As representações ${ }^{7}$, construídas por matemáticos e experts em diferentes tempos históricos sobre a matemática que deveria ser ensinada nas escolas, circulam no meio educacional. Dessas representações, fazem os professores, as suas apropriações, construindo novas representações. Serão elas - as representações elaboradas pelos professores - as responsáveis por guiar práticas que irão dar significado às ações didático-pedagógicas dos mestres em sala de aula. $\bigcirc$ conhecimento dessas representações sobre o passado da 
educação matemática deve possibilitar a realização de práticas de ensino e aprendizagem de melhor qualidade em tempos presentes. Nessa direção o passado não deve ser algo a ser esquecido ou idealizado de modo ingênuo, anacrônico. Muito ao contrário: o passado deve estar sempre presente. Assim sendo, este estudo intenta apresentar resultados de pesquisa sobre as transformações sofridas pela Aritmética e pela Geometria, ao longo do tempo, como modo de melhor referenciar propostas para o ensino atual desses saberes, que são ensinados nos primeiros anos escolares.

\section{Sobre o cálculo, a aritmética dos anos iniciais}

No cotidiano de nossas vidas, temos necessidade de fazer cálculos, aproximações, comparações e tantas outras atividades diretamente ligadas ao trabalho com números. A aquisição desses processos é diferente para as pessoas escolarizadas e para aquelas que não passaram pelo ensino formal. E, além disso, o uso dos números no dia a dia se dá de modo diverso nesses dois casos. Assim, é possível dizer, desde logo, que há uma Aritmética aprendida na vida comum - entendida como a necessidade criada historicamente de aritmetizar a realidade; e, uma Aritmética escolar - fruto também histórico dos processos de ensino e aprendizagem da Matemática.

\section{Sobre a aritmetização da realidade}

Noutros tempos, os primeiros anos escolares eram chamados de escola de primeiras letras ou escola do ler, escrever e contar. $\bigcirc$ "contar" traz a referência do conhecimento matemático (aritmética) presente desde as primeiras lições escolares. Escrever, ler e contar guarda muito mais semelhanças do que comumente pensamos, e, talvez, por isso mesmo, possam ser tratados como sendo as primeiras letras. De fato, essas habilidades, igualmente, operam com sistemas simbólicos e tais sistemas representam convencionalmente realidades abstratas por meio de signos concretos, permitindo combinações e transformações geradoras de novos sentidos ou novos fatos. (MORAIS, 2011 ).

As palavras, incluindo as palavras de algarismos, são símbolos culturais arbitrários. Cada uma reúne e condensa, num pequeno objeto mental, diferentes informações e, sobretudo, segmenta a continuidade inerente às 
representações analógicas pré-verbais. Aquilo a que chamamos habitualmente aprendizagem da leitura e da matemática, ou mais restritamente da aritmética, é, respectivamente, a aprendizagem de sistemas de representação simbólica de fonemas e de quantidades numéricas. (MORAIS, 20111 .

Vistas as semelhanças, em termos amplos, dos saberes fundamentais presentes na escola de primeiras letras, entendemos a razão por que a Aritmética faz parte, de modo inconteste, dos ensinos escolares e, em especial, dos primeiros anos. Qual o sentido de sua existência nos currículos escolares? A sua particularidade? A explicação para isso reside na importância em nos apropriarmos da Aritmética como uma forma de agir na realidade que nos cerca. Assim, a justificativa é válida, por certo, para muitas outras rubricas escolares. É, portanto, imperioso tratar da contribuição da Aritmética, de modo específico. Assim, em termos mais precisos, cabe-nos dizer que a Aritmética liga-se à nossa necessidade de aritmetizar o real, isto é, aritmetizar situações da realidade da vida:

A aritmetização e a matematização das situações consistem em elaborar representações simbólicas quantificadas do real e depois em operar (seguindo regras precisas) sobre estas quantificações, para que os resultados das operações (aritméticas) efetuadas sobre as representações simbólicas forneçam uma aproximação aceitável (cujo desejável grau de adequação, para, além disso, terá sido fixado) dos resultados que seriam efetivamente obtidos pela aplicação no real de ações correspondentes às transformações simbólicas (acréscimos, decréscimos, repartições etc.). (FAYOL, 2010, p. 131.

Desse modo, achamos possível através da Aritmética (um sistema de símbolos e de regras) calcular resultados que podem e devem estar relacionados com o que esperamos encontrar no mundo real. Assim, se Joãozinho tem 25 figurinhas para completar o seu álbum de 100, não será preciso folhear o álbum, e contar uma a uma, para verificar se ali estão 75. Basta que sejam utilizados os símbolos 100 e 25, e uma operação (subtração) que se irá obter a quantidade esperada.

Por trás da simplicidade do exemplo mencionado está uma longa marcha da vida humana que chega à época moderna. Assim é que o processo de interagir com a realidade, visando aritmetizá-la, tem origem distante: 
As origens deste processus devem procurar-se na cultura árabe, no seu gosto pela formalização à experiência sensível, na preocupação de transformar o real físico e de apreender o sentido profundo dessa transformação. Para o árabe, ao invés do pensamento filosófico grego que considerava a natureza como algo não passível de medida exata, tudo é medida, rigor e precisão. Esta visão contaminou a cultura cristã e todo o esforço vai orientar-se no sentido da compreensão profunda do número e da sua racionalidade. Arimetizar o real, ou melhor, desenvolver técnicas de cálculo em conexão com as transformações do mundo sensível, na linha do qual se encontram as tentativas para arimetizar a própria álgebra, eis a atitude que atravessa toda a ldade Média europeia como preocupação obsessiva. (ALMEIDA, 1994, p. 169-170).

A aritmetização do real, em sentido lato, é elemento da vida cotidiana das pessoas (crianças, adolescentes ou adultos). Todos nós nos defrontamos, a todo tempo, com situações que nos exigem comparações, trocas, compras, medidas etc. Essas situações variam em complexidade. A vida do dia-a-dia leva adultos, adolescentes e crianças a incorporarem rotinas que the são úteis para a resolução de problemas ligados às suas necessidades imediatas. Atentemos para o seguinte exemplo:

Freguês: Quanto é um coco?

Vendedor: Trinta e cinco.

Freguês: Quero dez cocos. Quanto é dez cocos?

Vendedor: (Pausa) Três são 105, com mais três é 201. (pausa) Tá faltando quatro. É ... (pausa) $315 \ldots$ parece que é 350. ICARRAHER; CARRAHER; SCHLLEMANN, 1988, p. 32).

$\bigcirc$ processo de utilização de elementos aritméticos permite que possamos resolver uma gama maior ou menor de problemas, a depender das situações e necessidades da cultura em que vivemos. É preciso atentar, no entanto, que a aritmetização da realidade, a partir das necessidades da vida cotidiana, é processo muito rico, porém limitado. Por certo, o mesmo jovem vendedor de cocos levado a uma situação diversa da que está imerso não teria respostas satisfatórias para problemas aritméticos de natureza diferente daquela que mantém a sua própria subsistência. Assim, a vida fora da escola ensina cálculos, mostra-nos situações de confronto em que se desenvolvem rotinas para aritmetizar a realidade, mas essas habilidades adquiridas e interiorizadas 
não são suficientes para a construção da autonomia daquele que precisa avaliar e fazer julgamentos das mais diversas situações que poderá enfrentar ao longo de sua existência. Há, dessa forma, a necessidade da aprendizagem da Aritmética na escola.

A aprendizagem da Aritmética escolar envolve um distanciamento da realidade imediata, do cotidiano em que estão imersos crianças, adolescentes e adultos, de seus problemas rotineiros que envolvem uma aritmetização do real, para a posse de símbolos e regras para com eles poder operar.

\section{Sobre a aritmética escolar}

Diferentemente do que ouvimos comumente, o ensino escolar da Aritmética não se organiza por situações práticas encontradas no dia a dia das pessoas. Não é pela coleção de situações reais como a da venda de cocos, da compra de mercadorias no supermercado, do troco na passagem de ônibus etc. que está estruturado o conjunto de conhecimentos aritméticos a ser ensinado nas escolas:

[...] ao contrário das formações profissionais que prevalecem durante muito tempo, a escola não tem como objetivo a aprendizagem de aptidões imediatamente passíveis de serem exploradas na vida corrente. Pelo contrário, inscreve-se numa perspectiva a longo prazo que procura dotar os indivíduos de conhecimentos e de saberes gerais que lhes permitam uma adaptação cognitiva e social a situações complexas, afastadas no tempo, largamente desconhecidas e móveis, tanto mais que a expectativa de vida aumenta. Segue-se que os ensinamentos têm necessariamente um caráter abstrato, já que visam a flexibilidade, a generalização e a integração em curricula que comportam progressões a longo prazo. Assim, a preocupação de ensinar as operações aritméticas (adição, subtração etc.) e não simplesmente procedimentos de resolução associados às ações (juntar, retirar) afasta o ensino escolar das formações que visam a aquisição de saberes imediatamente eficazes e utilizáveis. (FAYOL, 2010, p. 18).

Na escola, nos processos didáticos e pedagógicos, a Aritmética torna-se Aritmética escolar. Para além do sentido matemático do corpo de símbolos e operações com eles a serem realizadas, a Aritmética escolar resulta no 
produto de um diálogo secular entre os mestres e seus alunos, um código entre duas gerações, que lenta e minuciosamente, é elaborado em conjunto, de modo que uma das gerações possa transmitir à outra, uma cultura determinada. (CHERVEL, 1990). Essa perspectiva está descrita em um texto do historiador da educação André Chervel, que vem constituindo referência fundamental para o estudo das disciplinas escolares. Esse pesquisador traz contribuição fundamental, com base em suas pesquisas sobre a gramática escolar francesa, à análise dos conteúdos escolares. Chervel, de modo original, analisa, historicamente, as relações entre ciência, pedagogia e as disciplinas escolares. Para Chervel, a forma consagrada de tratamento dos ensinos escolares pode ser sintetizada, considerando-se que:

Na opinião comum, a escola ensina as ciências, as quais fizeram suas comprovações em outro local. Ela ensina à gramática porque a gramática, criação secular dos linguistas, expressa a verdade da língua; ela ensina as ciências exatas, como a matemática, e, quando ela se envolve com a matemática moderna é, pensa-se, porque acaba de ocorrer uma revolução na ciência matemática; ela ensina a história dos historiadores, a civilização e a cultura latina da Roma antiga, a filosofia dos grandes filósofos, o inglês que se fala na Inglaterra ou nos Estados Unidos, e o francês de todo o mundo. (CHERVEL, 1990, p. 180).

Contrapondo-se a essa concepção comum, os estudos de Chervel apontam a originalidade das produções escolares, em termos de elaboração das disciplinas. Elas são o resultado histórico do que a escola produz ao longo dos séculos de sua existência. E, mais: ajunte-se a isso, uma verdadeira revolução epistemológica na forma de analisar os conteúdos escolares. $\bigcirc$ tema surge quando o autor aborda as relações entre ciência, pedagogia e disciplinas escolares. A concepção comum existente sobre os ensinos escolares, mencionada anteriormente, ancora-se, igualmente, num modo clássico de perceber a pedagogia: um lubrificante que age sobre os conteúdos produzidos pela comunidade científica, de modo a vulgarizar a ciência para crianças e adolescentes. Tratar-se-ia de uma metodologia, de modos de trabalhar os conteúdos de maneira a que pudessem ser ensinados. Segundo tal visão, de um lado estão os conteúdos científicos e, de outro, os métodos. Em suma: Ciências apartadas da Pedagogia. 
No entanto, o trabalho de André Chervel rompe com essa perspectiva na medida em que alerta para o fato de que:

Excluir a pedagogia do estudo dos conteúdos é condenar-se a nada compreender do funcionamento real dos ensinos. A pedagogia, longe de ser um lubrificante espalhado sobre o mecanismo, não é senão um elemento desse mecanismo; aquele que transforma os ensinos em aprendizagens. (CHERVEL, 1990, p. 182).

A construção do conhecimento escolar é também explicada pelo pesquisador Thomas Popkewitz. Esse autor faz uso da metáfora da alquimia, para analisar o significado dos saberes presentes na escola. $\bigcirc$ autor, de modo semelhante a André Chervel, traz a Pedagogia para o centro das atenções:

A pedagogia pode ser pensada como análoga à metalurgia medieval que procurou converter metais comuns em ouro. Uma conversão mágica ocorre à medida que o conhecimento acadêmico é conduzido para o espaço do ensino. Os princípios governadores da alquimia já não são os da matemática ou da ciência mas os da pedagogia. A focalização na comunicação das crianças e a seleção do conteúdo curricular ajustam-se à organização dos níveis escolares, dos horários das turmas, e aos modelos do desenvolvimento das crianças para o ensino primário e secundário. A alquimia é uma parte necessária do ensino. A pedagogia traduz o conhecimento acadêmico para o mundo do ensino. Porque as crianças não são matemáticos nem historiadores, as ferramentas de tradução são necessárias para a instrução. (POPKEWITZ, 201 1, p. 92).

Para além de utilizar a metáfora, Thomas Popkewitz elabora um corpo de explicações visando evidenciar que práticas ałuais conjugam-se para a transformação de "metais comuns em ouro", ou a Matemática em Matemática escolar. Do ponto de vista do autor, essas práticas envolvem:

(a) uma re-imaginação da matemática na pedagogia; (b) a psicologia como o 'olho' pedagógico; (c) a resolução de problemas como um mecanismo de organização para classificar e governar a criança; (d) fabricar a criança que resolve problemas como uma espécie humana para intervenções pedagógicas; e (e) investigar na sala de aula 'comunidades' e processos de comunicação que 
relacionam a auto realização pessoal com as capacidades públicas ou coletivas. (POPKEWITZ, 201 1, p. 100).

Constatamos, assim, nesta breve menção aos estudos de André Chervel e Thomas Popkewitz, que a Pedagogia exerce papel central na produção dos saberes escolares. Tal constatação leva ao interesse de analisar as suas transformações em face das mudanças pedagógicas. Em específico, para o que cabe a este texto, vale perguntar, neste ponto da discussão: como a matemática escolar dos anos iniciais altera-se em meio às diferentes vagas pedagógicas? $\bigcirc$ texto que segue intenta dar resposta à questão, buscando discutir, em perspectiva histórica, as mudanças na aritmética escolar. E, mais adiante, na geometria escolar.

\section{A aritmética escolar tradicional, de antes de anteontem, de ante- ontem, de ontem...}

As considerações que seguem constituem resultados do desenvolvimento de projetos de pesquisa, já encerrados e, também, de pesquisas em desenvolvimento. Apresentamos, nas linhas abaixo, sínteses desses resultados, visando caracterizar melhor a trajetória de mudanças da aritmética escolar, em meio a diferentes vagas pedagógicas. Dentre elas, destacamos o que ficou conhecido como ensino tradicional, ensino ativo, escola ativa e matemática moderna.

\section{A aritmética escolar tradicional: a aritmética de outros tempos}

É senso comum pedagógico a caracterização "tradicional". A sua conceituação do ponto vista dos estudos históricos ocorre ao final do século XIX, com a chegada de uma nova pedagogia, denominada intuitiva. $O$ surgimento do novo, da nova pedagogia estabelece-se no contraponto àquilo que esse novo não é. Na afirmação da nova pedagogia intuitiva, é imperativo abandonar as formas antigas do ensino dos conteúdos escolares. Longe deve ficar o tratamento da aritmética no sentido de mecanicamente decorar tabuadas e cantálas sem compreender os seus resultados². Isso é algo que, 
parodiando Barbosa, "cumpre erradicar". (BARBOSA, 1946, p. 36). Assim, na rejeição ao passado, fica caracterizado o ensino tradicional.

Para além de pensar a aritmética tradicional como resultado de uma metodologia, de uma didática, a pedagogia que antecede a vaga intuitiva, estrutura a aritmética escolar de modo lógico-matemático. Dessa maneira, o aluno deverá seguir a organização interna dos conteúdos, para a aprendizagem desse saber escolar. E, o modo disso ser realizado passa por crítica severa na emergência do ensino intuitivo. Sobretudo da lavra de Rui Barbosa, emerge e consolida-se a representação do ensino tradicional: trata-se de um ensino livresco, de repetição por processos mecânicos.

\section{A aritmética de antes de anteontem: a aritmética intuitiva, uma aritmética do ensino ativo}

A chegada do ideário do ensino intuitivo, como experimental e concreto, constrói uma representação do passado do ensino de Aritmética no primário, profundamente negativa. Trata-se de um ensino abstrato, com uso quase exclusivo de processos de memorização, sem utilidade. Também ela, a Aritmética, imersa nessa escola ineficiente, deve ser transforma

da. Ensinada e estruturada de outro modo, com materiais em que o ensino possa ser o mais concreto possível. Buscamos a ultrapassagem do modo verbalístico, que segue a lógica interna do conteúdo da aritmética escolar, para a apropriação da aritmética pela via dos sentidos. Na chegada da pedagogia intuitiva podemos ler a mudança na matemática escolar, por exemplo, a partir do conceito de número: de quantidade a ser memorizada, pela via das tabuadas a serem conhecidas de cor, a conceituação de número passa a quantidade a ser sentida. Pouco importa - do ponto de vista escolar - qual seja a concepção matemática de número: Seu papel no ensino é seu próprio definidor! Importa o significado que tenha para as práticas pedagógicas desse tempo. Passa-se de uma representação de que a escola tradicional promovia a aprendizagem de número pela sua característica de quantidade a ser memorizada, para aquela em que o conceito de número a ser aprendido é o de quantidade a ser sentida, nos moldes da pedagogia intuitiva. E essa não é uma alteração externa, somente de metodologia, "lubrificando" (CHERVEL, 1990) de outro modo o ensino de número: trata-se de uma alteração epistemológica, 
da construção de outro significado para esse saber e esse conceito. $\bigcirc$ ensino intuitivo da Aritmética, da numeração, levará em conta a Lição de Coisas. Assim, cada número, tratado inicialmente de modo oral, será gravado nas mentes infantis, associando-o sempre às coisas. As coisas darão lições sobre os números e organizarão a aritmética escolar ${ }^{3}$. A atividade defendida no livro didático de Trajano de (1889 ou 1890, p. 17) evidencia a proposta:

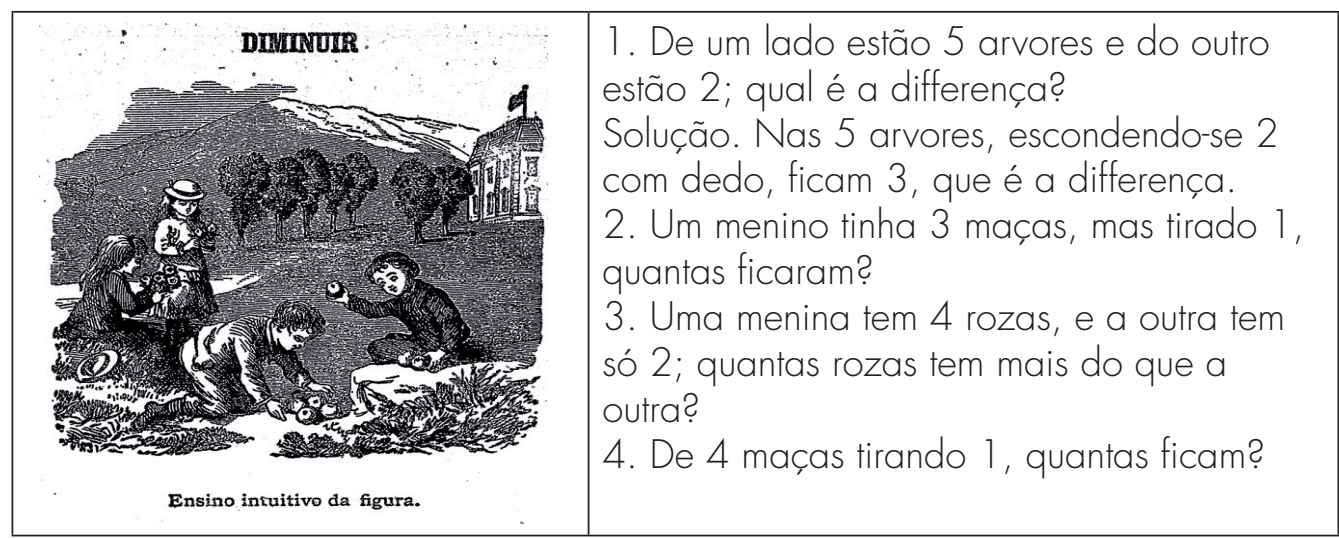

Fonte | Aritmética primária (Antonio Trajano)

Essa nova aritmética, fruto da alquimia (POPKEWITZ, 2011 ) que junta matemática e pedagogia das lições de coisas, irá consagrar-se como "ensino ativo" da matemática. Logo, porém, um novo tempo chega, e com ele a emergência da "escola ativa" 4 , com uma aritmética reconstruída, reorganizada, no âmbito da Escola Nova.

\section{A aritmética de anteontem: a aritmética da Escola Nova, uma aritmética da escola ativa}

Novos ventos pedagógicos sopram do estrangeiro, e uma nova pedagogia se instala: chegam os tempos de Escola Nova. Entra-se num período de dar ao processo educativo novas bases, novos paradigmas. Surge a renovação pedagógica e o desafio de romper com os modos considerados tradicionais. Há necessidade de outros métodos e programas. Emerge um novo modo de pensar o papel do professor no processo educativo: a criança deve 
ser o centro do ensino. $O$ saber psicológico surge como condutor da pedagogia. Depois da memorização, da aprendizagem pelos sentidos, chegou a hora do processo de ensino considerar a ação. Será somente pela ação dos alunos que se dará a aprendizagem. E, mais: essa ação, vontade própria dos educandos irá mobilizá-los para a aprendizagem. No caso do ensino de matemática, essa ação terá origem naquilo que os discursos direcionados a professores, contidos nas revistas pedagógicas, passam a caracterizar como "resolução de problemas da vida real". Esse discurso parece ter vida longa. $\bigcirc$ Programa de Aritmética de 1949, orientador do ensino primário no estado de São Paulo, coloca, dentre os quatro objetivos, o seguinte:

Preparar a criança para a vida, tornando-a capaz de resolver os seus problemas todas as vezes que impliquem o uso do cálculo e da medida; Desenvolver a habilidade de analisar e resolver problemas simples, relacionados com as experiências de sua vida infantil e, desde ceda, interessa-la nos problemas econômicos da família e do ambiente em que vive, tornando, assim o ensino prático e educativo. (PROGRAMA DE SÃO PAULO apud SILVA, 2011$, p. $)$

Em meados dos anos 1950, em livro de metodologia para o ensino de matemática no curso primário, a professora-autora Irene de Albuquerque, catedrática de Prática de Ensino do Instituto de Educação do Distrito Federal, logo na Introdução da obra, postula:

Toda criança de inteligência normal, sem ser brilhante, é capaz de aprender, com relativo êxito, as noções dos programas de Matemática da escola primária; pode, ainda, resolver com certa facilidade os problemas de Matemática que a vida the apresenta. (ALBUQUERQUE, 1960, p. 7).

A caracterização dessa aritmética ativa se dá, portanto, na proposição de que os alunos envolvam-se na resolução de problemas que demandem ferramentas aritméticas para a sua resolução. Muito antes de pensarmos na elaboração de uma das tendências atuais da Educação Matemática - a de resolução de problemas, como uma metodologia de ensino, os ventos escolanovistas, tentando varrer propostas consideradas antigas, tradicionais, já apregoavam a seleção e organização de atividades que fizessem sentido para o aluno. E elas deveriam ser propostas sob a forma de problemas. E os 
problemas constituiriam elementos centrais a fazer parte da metodologia de projetos, na dos chamados centros de interesse. $\bigcirc$ exemplo a seguir pertence ao livro de Alfredina de Paiva e Souza (1937, p. 98).

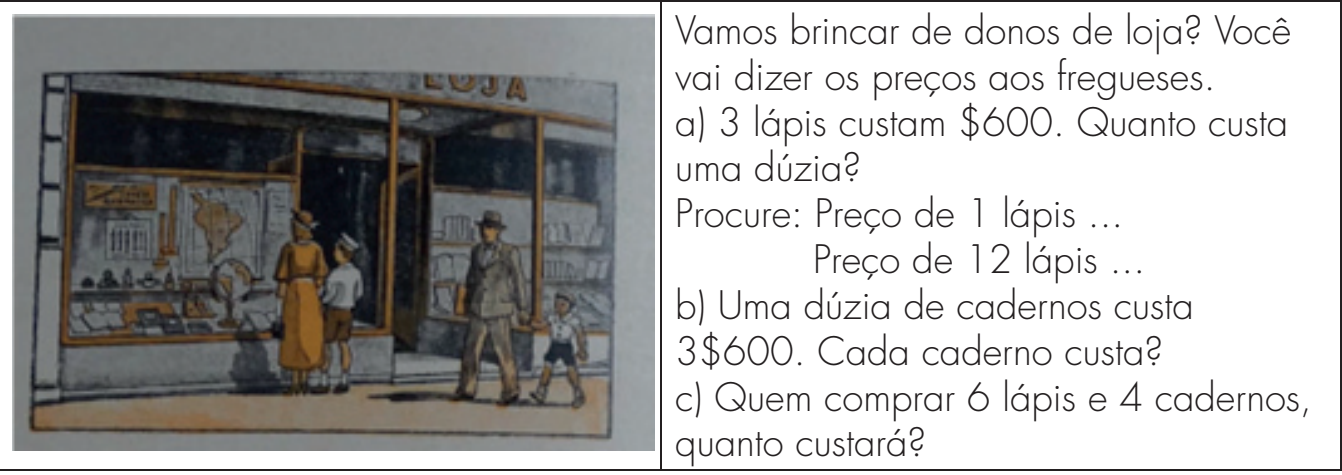

Fonte | Nossa aritmética $3^{\circ}$ ano (Alfredina de Paiva e Souza)

\section{A aritmética de ontem: quando a matemática se tornou moderna}

Bem viva está na memória de muitos educadores matemáticos a época do chamado Movimento da Matemática Moderna. Os preâmbulos da modernidade do ensino da Aritmética para crianças mostram que vagas pedagógicas são responsáveis diretas pelas alterações no modo de conceber o que deve ser ensinado nos anos iniciais. Parte-se de um tempo onde a aritmética escolar dá lugar privilegiado à memória do cantar a tabuada; passa-se pelas lições que as coisas podem dar sobre numeração e chega-se nas ideias escolanovistas, em que a resolução de problemas da vida real das crianças pode levar à aprendizagem da aritmética escolar. Em todas essas épocas tem-se, logo ao início dos trabalhos escolares, o tratamento do sistema de numeração. Ele é o primeiro tema de estudos da matemática para crianças.

A modernidade altera completamente essa organização de ensino. A análise da trajetória de modificação da matemática escolar para crianças a partir de finais da década de 1950 revela o amparo de um movimento internacional - o Movimento da Matemática Moderna - como sustentação para os discursos e práticas da modernidade no ensino da Aritmética escolar. Esse Movimento conjuga transformações na Matemática propriamente dita 
e a afirmação de trabalhos da psicologia cognitivista. Ambos imersos num tempo de predomínio do estruturalismo, como modo de pensar a produção científica. Trata-se de uma vaga pedagógica com características diferentes das anteriores. Os estudos e ações dos matemáticos, de grupos de matemáticos exercem papel fundamental nas transformações da matemática escolar. E não se trata somente da matemática escolar de níveis próximos ao ensino universitário: está em questão a matemática para crianças, aquela dos primeiros anos escolares. Como resultado desse contexto, a organização curricular e o ensino de matemática para crianças sofrem transformação radical: a aritmética não poderá mais ser ensinada logo ao início da escolaridade. Número é elemento abstrato, que deve ficar longe das crianças, em seu primeiro contato com a Matemática. Número é propriedade. E, nesse caso, altera-se a ordem vigente há séculos. Desse modo, para os primeiros contatos escolares da criança com a matemática está reservada a Álgebra e não mais a Aritmética. No princípio, são as relações, depois os números. A aproximação com os elementos algébricos que decorre, até então, na escola elementar, de uma generalização da Aritmética é abandonada. Passa ao primeiro plano, a Álgebra, a ser seguida pela Aritmética. As estruturas algébricas para crianças, em seus primeiros ele192 mentos, passam a se constituir em novos conteúdos para o currículo escolar, de maneira a ser possível ensinar número. E, esses outros conteúdos constituem novos elementares - entendidos como novas formas basilares do conhecimento - uma nova matemática escolar, portanto - que permite o acesso ao conceito de número, à sua caracterização como uma propriedade dos conjuntos. Os novos conteúdos elementares são construídos a partir da Teoria dos Conjuntos. Com ela, ao tempo do Movimento da Matemática Moderna, sustenta-se a ideia da aprendizagem do novo conceito escolar do que é número. Primeiro o ensino de elementos da Teoria dos Conjuntos; depois, os números, o sistema de numeração, as operações aritméticas. E os conjuntos constituem ícone desse tempo escolar: um tempo quando a escola do "ler, escrever e contar" transforma-se na escola do "ler, escrever e trabalhar com conjuntos". $\bigcirc$ "contar", o ensino do sistema de numeração, não mais é o primeiro conteúdo da matemática para crianças, ele é substituído pelos conjuntos. Primeiro, a Álgebra; depois, a Aritmética. As duas atividades abaixo constam do livro Curso Moderno de Matemática de Liberman, Franchi e Bechara (1967). 

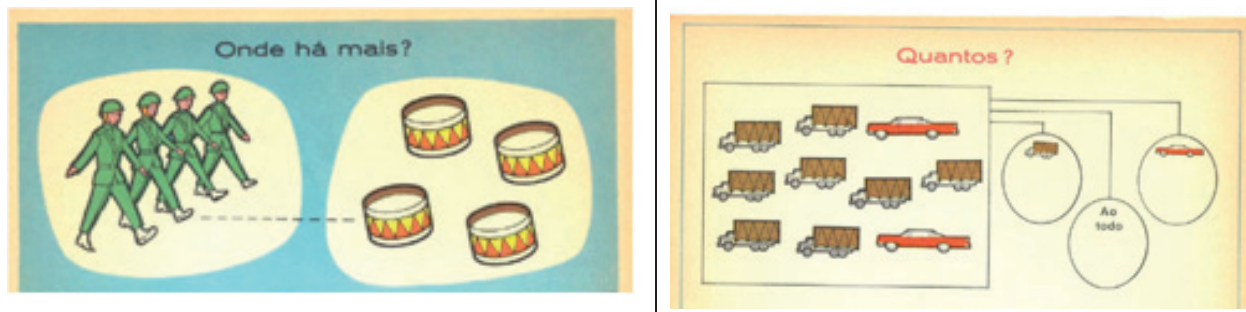

Fonte | Curso Moderno de Matemática para a escola elementar (Liberman, Franchi e Bechara)

\section{Sobre o papel da geometria nos anos Iniciais}

mundo em que vivemos é repleto de representações geométricas, de figuras que guardam determinadas propriedades, sejam elas de paralelismo, de medidas, de simetrias e outras tantas relações que, a todo o momento, identificamos no nosso cotidiano. Podemos dizer que a geometria está presente na natureza, nas artes, na ciência. Para Freudenthal lapud CLEMENTS, 1998, p. 03), "Geometria é o espaço compreendido... espaço que a criança vive, respira e se move. $\bigcirc$ espaço que a criança deve aprender a conhecer, explorar, conquistar, a fim de viver, respirar e mover-se melhor nele."

Entretanto a maneira como cada um identifica e faz a leitura dessas relações depende de um processo de escolarização. Nos Parâmetros Curriculares Nacionais, os conceitos geométricos são considerados partes importantes do currículo por desenvolver uma forma particular de compreender, descrever e representar, de forma organizada, o mundo em que vivemos. A geometria também é um campo fértil para se trabalhar com situações-problema, contribui para a aprendizagem de números e medidas, por estimular a observação, percepção de semelhanças e diferenças, identificar regularidade. (Parâmetros Curriculares Nacionais, 1997). Para além das finalidades de uma formação básica, a formação de profissionais no campo de geometria é um imperativo ditado pelo desenvolvimento tecnológico e científico atual. (LIMA; CARVALHO, 20101.

A discussão atual do papel e importância da geometria nos anos iniciais traz consigo duas grandes habilidades a serem construídas pelos processos didático-pedagógicos levados na escola. A primeira, iá antiga, refere-se 
à compreensão e exploração do nosso mundo, que significa a leitura das diferentes representações geométricas na vida cotidiana. A segunda diz respeito a mover-se melhor num determinado espaço e tal habilidade envolve outras funções e conteúdos que passam a ser incorporados no rol de conteúdos geométricos. Talvez essa seja uma justificativa de que a geometria nos anos iniciais hoje se denomina como Espaço e Forma. De um lado, o trabalho pedagógico voltado para questões não propriamente geométricas, mas que dizem respeito à apropriação do espaço; de outro, os temas definidores da geometria ligados à abstração das formas geométricas.

Em relação à compreensão e leituras dos espaços, os Parâmetros Curriculares elencam conteúdos como localização e movimentação de pessoas ou objetos no espaço, com base em diferentes pontos de referência e algumas indicações de posição, de direção e sentido; descrição, interpretação e representação tais localizações e movimentações por terminologia própria. Ler um mapa, localizar-se nele e saber locomover-se a partir dessa interpretação é atitude esperada na construção da cidadania e cabe ao processo de escolarização o desenvolvimento de tal competência.

Desde a pré-escola, as crianças podem discriminar características 194 como fechado e aberto, e crianças mais velhas identificam linhas retas de lados curvos e, num momento posterior, ainda reconhecem formas como quadrados e losangos. Os pesquisadores Piaget e Inhelder explicam que o entendimento de formas (espaço de representação) requer das crianças a coordenação de ações sistematicamente. Crianças novas, por exemplo, apreendem uma parte somente da forma, ou talvez duas partes sem relacionar as duas percepções. Crianças maiores conectam uma percepção a outra, construindo uma imagem mental completa da forma. Assim, para criar ideias sobre as formas, as crianças precisam agir e conectar suas ações. (CLEMENTS, 1998).

Uma questão central e importante é que a construção das ideias sobre formas não se dá de maneira passiva. Olhar e nomear não é suficiente; elas devem explorar as partes e características das formas. A pesquisa educacional e psicológica mostra que as crianças precisam explorar as formas de modo completo, incluindo as suas partes, características e transformações. Precisam representar as formas em desenhos, mapas, dramatizações e linguagem verbal. As formas exploradas devem incluir exemplos e contraexemplos ricos e de diferentes categorias de formas. Em síntese, concluímos que crianças efetivamente 
aprendem sobre espaço e forma através do engajamento ativo com materiais manipuláveis, desenhos e computadores. (CLEMENTES, 1998).

Diante desse processo complexo de construção e criação de ideias sobre espaço e forma nas crianças, fica designada para a escola a tarefa de desenvolver um processo de ensino que permita essa compreensão. Não basta o olhar, o manipular simplesmente, o contato com as muitas representações geométricas que nos cercam no nosso cotidiano para compreender, descrever e representar de forma organizada o mundo em que vivemos. A manipulação, por si só, não é suficiente; ela deve ser empregada num contexto de tarefas educativas visando engajar ativamente os pensamentos das crianças com a orientação do professor. (CLEMENTS, 1999).

Evidenciamos, a partir das discussões apresentadas, a relevância dos métodos empregados para o processo de ensino e aprendizagem dos conceitos geométricos. A cada tempo, os resultados de pesquisas, em especial, do campo da psicologia, alteram a maneira de construir as ideias de espaço e forma, e, consequentemente, modificam as orientações para as práticas pedagógicas propostas para o ensino de geometria dos anos iniciais. A geometria escolar, para ser compreendida, requer, para além do conhecimento de saberes geométricos, a análise de como os métodos de ensino se configuram aos saberes em questão.

\section{Geometria e realidade}

Como já falamos, a construção das ideias de espaço e forma deve se iniciar pela manipulação e visualização de objetos do mundo físico, da realidade. Da mesma forma, são importantes as atividades que envolvem representações gráficas desses objetos. Estão em jogo três tipos de objetos: objetos geométricos, que são conceitos abstratos, objetos físicos, presentes na realidade e objetos gráficos, que representam os objetos físicos e geométricos. (LIMA; CARVALHO, 2010).

A passagem do físico, perceptível e palpável para o abstrato, é um dos objetivos centrais do ensino e da aprendizagem da geometria e os objetos gráficos constituem-se em um importante nível intermediário de abstração entre os objetos físicos e as entidades puramente matemáticas. Entretanto, se, por um lado, os objetos gráficos cumprem um papel intermediário na construção dos 
objetos geométricos, por outro lado, destacamos que os objetos abstratos são concebidos mentalmente e só podem ser representados imperfeitamente em duas ou três dimensões. (LIMA; CARVALHO, 2010).

Como exemplo, a compreensão do objeto geométrico cubo pode ser construída a partir da visualização e manipulação de objetos físicos como um dado ou sua representação gráfica. Tanto o cubo como a representação gráfica do cubo são perceptíveis pelos sentidos, mas o cubo não, pois é uma entidade ideal, concebida com base em definições e em raciocínios lógicos. (LIMA; CARVALHO, 2010).

\section{A geometria escolar}

A geometria constitui-se como um campo científico da matemática e, desta forma, reúne um conjunto de saberes sistematizados e organizados. Tratando-se da geometria euclidiana, é possível dizer que esse saber não é mais passível de pesquisa matemática, tendo ficado inalterável e sem mudanças do ponto de vista conceitual. No nosso exemplo anterior, o objeto geométrico

196 denominado cubo é um dos conceitos presentes na escola dos anos iniciais e que não se modifica. Porém o objeto geométrico cubo, no ambiente escolar, sofre muitas alterações no decorrer das diferentes vagas pedagógicas, desde um tempo remoto, quando o aluno deveria decorar a definição de um cubo, tempo de ensino de perguntas e respostas. Um exemplo: o livro "Desenho Linear ou Elementos de Geometria Prática Popular" de Abílio Cesar Borges, de 1882, que apresenta o cubo como "[...] o paralelepípedo que tem as bases e as faces quadradas." (BORGES, 1882, p. 68).

Assim sendo, podemos evidenciar as diferenças entre dois saberes, um saber científico - e no caso da geometria euclidiana, um saber já morto para a pesquisa matemática - com definições, propriedades delimitadas, imutável; e um saber escolar, fruto de interações, apropriações das diferentes culturas escolares. A geometria escolar, relativamente à geometria euclidiana, armazenada nos Elementos, tem características distintas, ela se transforma e se recria a cada momento histórico. As legislações impostas, os métodos pedagógicos em circulação, a presença ou ausência de materiais didáticos, os manuais didáticos de orientação de seu ensino para professores são elementos que integram 
o processo contínuo de produção da geometria escolar em cada tempo. $\bigcirc$ conjunto desses elementos dá forma e significado à geometria escolar.

\section{A geometria tradicional, de anteontem, de ontem...}

As considerações que seguem, de maneira similar, as desenvolvidas para a aritmética, constituem resultados do desenvolvimento de projetos de pesquisa, já encerrados e, também, de pesquisas em desenvolvimento. Apresentamos, a seguir, sínteses desses resultados, visando caracterizar melhor a trajetória de mudanças da geometria escolar, em meio a diferentes vagas pedagógicas. Dentre elas, destacamos o que ficou conhecido como ensino tradicional, ensino ativo, escola ativa e matemática moderna.

\section{A geometria tradicional: a geometria de outros tempos}

A presença da geometria com um saber escolar para os anos iniciais de escolarização se dá exatamente na primeira legislação que regulamente a instrução no Brasil após a Independência. Ao contrário do que podemos imaginar, desde a escola de primeiras letras, denominação empregada ao ensino primário em tempos de Império, a geometria é parte integrante dos saberes a compor os diferentes programas. Apresenta-se como "noções mais gerais de geometria prática" e pode ser considerada como a geometria tradicional, por ser como a geometria mais antiga de nosso conhecimento e também por ser objeto de críticas em face das novas vagas pedagógicas.

Estudos mostram que a presença da geometria com um saber escolar não se dá de forma absolutamente consensual. Muitos são os debates entre os parlamentares encontrados nos Anais da Câmara e do Senado. De um lado, os defensores do ensino da geometria argumentam a importância de que os alunos peguem o compasso, descrevam um triângulo, considerando tarefa fácil e possível. De outra parte, os deputados contrários advertem de futuros problemas e dificuldades decorrentes de professores para lecionar a geometria, devido à carência de docentes com formação para o ensino de geometria no país. (VALENTE, 2012). 
A geometria prática que segue ao longo até quase o final do século XIX mantém uma forte ligação com outro saber escolar, o desenho. Por todo o período, percebemos que o desenho, por vezes, denominado desenho linear e a geometria seguem juntos nos programas, nos manuais de ensino. $\bigcirc$ desenho apoia-se nas construções de figuras geométricas, desenvolve as habilidades nos traçados que devem ser feitos à mão livre, porém com o objetivo de treinar mão e olhos, de modo a produzir figuras similares àquelas traçadas com régua e compasso. Tudo leva a crer que se busca no manual de Desenho um modelo para o ensino da geometria prática. Em síntese, a análise empreendida neste trabalho considera que o desenho linear constitui uma geometria para o curso primário. (VALENTE, 2012). O problema a seguir representa as construções realizadas no livro Primeiras noções de Geometria Pratica de Olavo Freire 11907, p. 35) e que cuja primeira edição foi publicada em 1894.

\begin{tabular}{|l|l|}
\hline Problema II - Traças a bissectriz de um angulo ou \\
dividilo em duas partes. \\
Do ponto A, com uma distancia qualquer, desc- \\
revamos o arco MN. Dos pontos M e N, como \\
centros, (fig. 35) e com uma mesma distancia de- \\
screvamos os arcos que determinam o ponto G, o \\
qual, ligado ao vertice do angulo, isto é ao ponto \\
A, nos dará a bissectriz pedida.
\end{tabular}

Fonte | Primeiras noções de geometria prática (Olavo Freire)

\section{A geometria de anteontem: a geometria intuitiva, uma geometria do ensino ativo}

Como já mencionamos, a chegada do método intuitivo, no qual as coisas ganham relevância e o conceito de aprendizado deve partir das coisas, provoca críticas a um processo de treino em traçar figuras geométricas à mão livre e domesticar os olhos nas medidas, que ganha o rótulo de tradicional. A geometria separa-se do desenho, que segue uma trajetória articulada com os traçados dos objetos naturais, da realidade da criança. $\bigcirc$ artigo da Revista de Ensino evidencia a cisão: 
$\bigcirc$ desenho é auxiliar da geometria pratica, e não é esta que nos leva a aprender o desenho. Um bom geômetra pode ser um optimo calculista theorico e não saber desenhar. E vice-versa, um bom desenhista pode nada saber de geometria. Nada há que justifique esse mau systema de fazer a criança traçar linhas rectas e curvas, ângulos, ovaes ou elipses para só depois apresentar-the os objectos. (N.M.E.S.5. 1913, p. 24 apud VALENTE, 2010).

No lugar de uma geometria atrelada ao desenho, de definições, considerada tradicional, propomos uma geometria também prática, contudo a prática ganha outro significado. O caráter prático se revela pelos traçados, porém com o uso dos instrumentos geométricos, como régua e compasso. As crianças iniciam os traçados nos $3^{\circ}$ e $4^{\circ}$ anos dos grupos escolares, nova denominação da escola primária no período em questão, realizam construções de figuras geométricas numa sequência de passos partindo de traçados simples, como transportar um ângulo até figuras elaboradas como o traçado de elipses.

A lição das coisas, a importância dos sentidos, da observação no processo de aprendizagem, também se revelam, em especial, nos dois primeiros anos de escolaridade, mas como a denominação de formas e não de estudo de geometria. As indicações para a matéria Formas ressaltam o estudo dos sólidos geométricos de modo intuitivo e prático; que se evitem os termos técnicos e o ensino teórico de noções abstratas e sugere-se que sejam feitos sólidos em argila e plastilina. Salientamos que o professor deve esforçar-se para gravar no espírito da criança a forma geral do sólido e, somente depois disso feito, levar os alunos a estudar as superfícies dos sólidos. A proposta é partir da observação do espaço para o plano. Tudo indica que a parte experimental e de observação, investigação dos objetos geométricos devem ser estudadas no início como uma preparação para o estudo da geometria que é desenvolvido num momento posterior, nos anos finais. Podemos dizer que a geometria do método intuitivo e ativo se caracteriza pela matéria de Formas, e para a geometria reserva-se um estudo prático de construções geométricas e definições.

Com a chegada da vaga escolanovista, no entanto, tudo indica que não houve ruptura. A geometria intuitiva para crianças não foi destronada para dar lugar a uma nova geometria escolar, uma geometria da escola ativa. Foi possível verificar que os livros didáticos não evidenciaram uma nova geometria. Muito ao contrário: eles reafirmaram a geometria intuitiva como modus 
operandi das orientações para as práticas pedagógicas escolanovistas. Na análise das obras, foi possível verificar ter sido perfeitamente possível unir a taquimetria - a geometria das lições das coisas - com as propostas escolanovistas, de um ensino de caráter experimental. $\bigcirc$ manual do professor Miguel Milano é exemplo emblemático: conjuga a praticidade e exploração do meio pelos alunos nos primeiros anos; e, nos dois últimos, apresenta a eles, processos de construção geométrica abstrata, sem exploração e compreensão. A atividade a seguir consiste em uma das primeiras lições do livro de Milano (1938, p. 128-129)

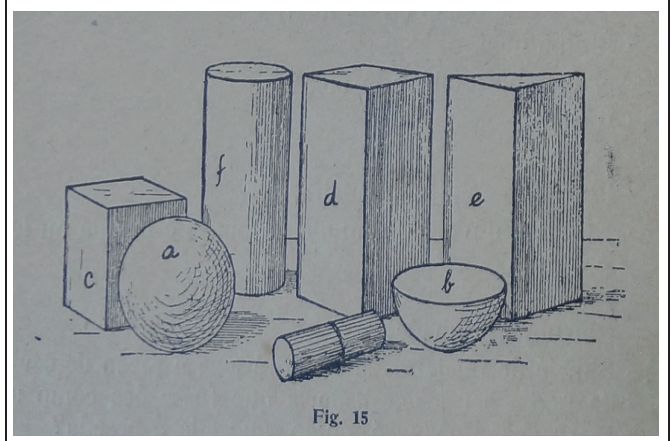

Hei de fazê-los conhecer, durante as lições. Vejamos. Que corpo é este, então?

- É um corpo sólido.

- Como se chama?

- Esphera.

- E que é esphera?

- Esphera é um solido de superfície curva, redondo como uma bola.

_ Muito bem! Conhecem vocês alguma coisa parecida com a esfera?

Fonte | Manual do ensino primário - $1^{\circ}$ ano (Miguel Milano)

\section{A geometria de ontem: uma geometria moderna}

Como já dissemos, a chegada do Movimento da Matemática Moderna se apresenta por mudanças significativas na maneira de compreender o processo de aprendizagem das crianças. A marca é do estruturalismo que procura conjugar os trabalhos da psicologia cognitiva e os estudos dos matemáticos. Na geometria, os estudos de Piaget e Inhelder publicados, em 1947, sobre a representação do espaço na criança apontam para o abandono da milenar ideia do ensino dos rudimentos dos Elementos de Euclides, voltando-se a atenção para os elementos da Topologia. Um dos primeiros a dar aplicabilidade aos estudos piagetianos no ensino da Matemática e, em especial da Geometria, é Zoltan Dienes, que reformula a proposta para o ensino de geometria: 


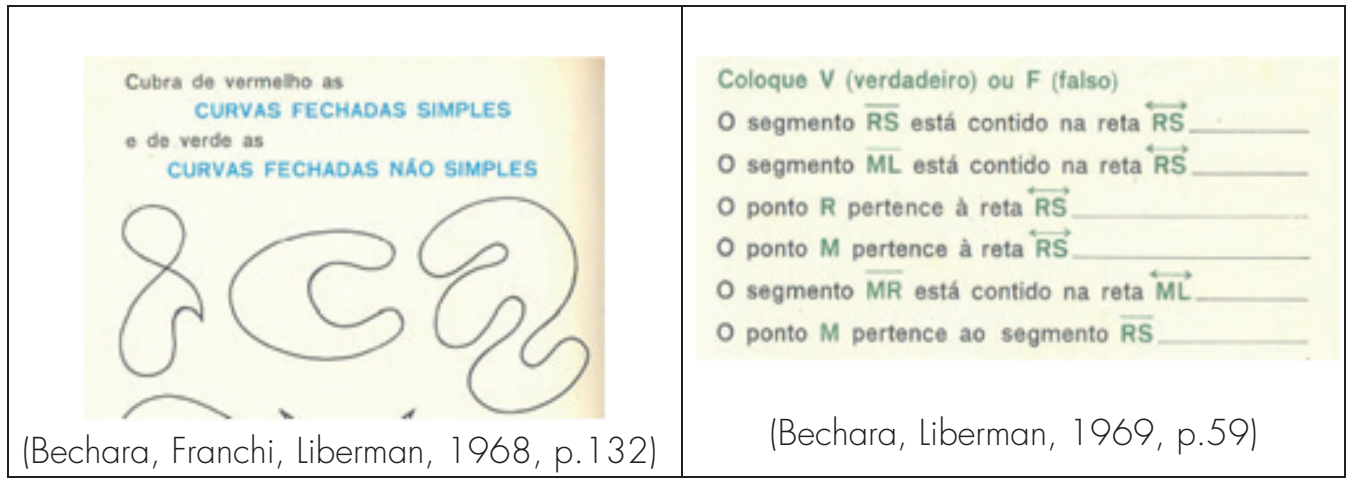

Fonte | Curso Moderno de Matemática para a escola elementar (Liberman, Franchi e Bechara)

\section{Considerações finais}

Como vimos anteriormente, a Aritmética e a Geometria, na sua forma escolar, sofreram transformações. Essas mudanças, ao longo do tempo, como se apregoou ao início, se forem apropriadas, sabidas pelo professor que ensina matemática, por certo, poderão provocar rupturas no modo como esse docente vê a matemática nos anos iniciais.

Em tempos atuais, no senso comum pedagógico, está muito presente, a dualidade tradicional versus moderno. Nessa dualidade, o ensino tradicional carrega todos os malefícios que poderão advir de um trabalho pedagógico de má qualidade. E, por moderno, estariam ações pedagógicas atualizadas, resultado de saberes contemporâneos sobre como deve ser ensinada a Matemática para os anos iniciais. A relação que os professores mantém com o passado, dessa forma, é extremamente redutora. O passado é visto como - lugar de erros cometidos, face ao presente cheio de sábias e inovadoras propostas. Se o professor que ensina matemática tiver, em sua formação, elementos de história da educação matemática poderá usar como ferramenta de trabalho uma representação diferente para a matemática escolar. Será ela vista como fruto do tempo pedagógico que a escola vive. Conformada por ele. A cada época, uma matemática a ser ensinada. Não mais imutável. E não mais dual em termos puramente metodológicos, preservando o conteúdo imutável. Cai por terra a ideia de que as mudanças no tempo são somente de modos de ensinar. Mudanças didáticas. Poderá ver a matemática presente no ensino 
elementar como uma alquimia da Pedagogia e da Matemática, resultando na forma escolar dos ensináveis aritmética e geometria. Nesse caso, o professor poderá ser incentivado a melhor precisar que expectativas contemporâneas estão postas para o ensino-aprendizagem dos saberes matemáticos. De outra parte, poderá ler nas propostas atuais ingredientes, elementos reconfigurados, resinificados dando lugar a propostas inovadoras que mantêm relações com o passado da educação matemática. Em suma, significa perceber que as práticas e propostas atuais estão cheias de historicidade. Que o passado está sempre presente.

\section{Notas}

1 Cabe, neste ponto, mencionar os estudos do historiador Roger Chartier sobre história cultural e o papel das representações. De pronto, explicitar o que o autor entende por representação: uma noção que articula três modalidades da relação com o mundo social: em primeiro lugar, o trabaTho de classificação e de delimitação que produz as configurações intelectuais múltiplas, através das quais a realidade é contraditoriamente construída pelos diferentes grupos; seguidamente, as práticas que visam fazer reconhecer uma identidade social, exibir uma maneira própria de estar no mundo, significar simbolicamente um estatuło e uma posição; por fim, as formas institucionais e objetivas graças às quais uns "representantes" (instâncias coletivas ou pessoa singulares) marcam de forma visível e perpetuada a existência do grupo, da classe ou da comunidade. (CHARTIER, 1990, p. 23).

2 Os pesquisadores Antonio Miguel e Denise Vilela caracterizam esse tempo escolar como uma etapa inicial, cunhada como mnemônico-mecanicista. Assim, "as perspectivas mnemônico-mecanicistas parecem ter predominantemente orientado os processos escolares de mobilização de cultura matemática na escola primária, em nosso país, durante toda a fase imperial. Embora a memória - aqui entendida não como uma faculdade ou processo mental, mas como uma característica inerente aos processos de comunicação humana e resultante do aperfeiçoamento desses mesmos processos na história - seja imprescindível para a realização de todas as atividades humanas, sabemos, entretanto, que o seu papel foi e continua sendo superdimensionado nos processos escolares de mobilização de cultura matemática. De certo modo, essa supervalorização da memória nos processos de aprendizagem humana parece remontar a Platão." (MIGUEL; VILELA, 2008, p. 991.

3 "As lições de coisas, forma pela qual o método de ensino intuitivo foi vulgarizado é, na realidade, a primeira forma de intuição - a intuição sensível. $\bigcirc$ termo foi popularizado pela Mme. Pape-Carpentier e empregado oficialmente durante suas conferências proferidas aos professores presentes na Exposição Universal de Paris, em 1867. Pestalozzi também é apontado como referência em lições de coisas, pelo fato deste ter captado os pontos essenciais da renovação pedagógica que as lições preconizavam "[...] as coisas antes das palavras, a educação pelas coisas e não a educação pelas palavras". Despertar e aguçar o sentido da observação, em todas as idades, em todos os graus de ensino, colocar a criança na presença das coisas, fazê-las ver, tocar, distinguir, medir, comparar, nomear, enfim, conhecê-las, este é o objetivo das lições de 
coisas no ensino primário e nos jardins de infância, cuja aplicação pode ser feita através de dois sistemas: como um exercício à parte ou uma lição distinta, tendo uma hora reservada para aplicação dentro do programa de ensino ou aplicada em todas as disciplinas escolares, inserida em todo programa de ensino. Sua difusão no final do século XIX gerou a produção de um grande número de manuais escolares para o ensino das lições de coisas, dentre eles podemos citar: Primeiras Lições de Coisas de Norman Allison Calkins, publicado originalmente nos Estados Unidos, em 1861 e traduzido por Rui Barbosa, em 1886 (...)http://www.histedbr.fae.unicamp. br/navegando/glossario/verb_c_licoes_das_coisas.htm - GLOSSÁRIO - Acesso em: 26 jan. 20121 .

4 Por ensino ativo entenda-se o processo escolar surgido nas últimas décadas do século XIX, relativo ao modo de como os saberes escolares deveriam ser trazidos ao aluno, considerando a atividade dos professores na realização de experimentos e no oferecimento de imagens e objetos que concretizassem a aula. Já a expressão escola ativa foi criada em 1917, difundindo-se mundialmente a partir de 1922, representando o deslocamento para os alunos o princípio da ação, atribuindo-lhes o protagonismo nas tarefas e na descoberta dos conhecimentos, através dos métodos de projeto e centros de interesse. (VIDAL, 2006).

5 Autor desconhecido.

\section{Bibliografia}

ALBURQUERQUE, Irene. Metodologia da matemática. Rio de Janeiro: Conquista, 1960.

ALMEIDA, António Augusto Marques de. A aritmética como descrição do real (1519-1679). Contributos para a formação da mentalidade moderna em Portugal. Lisboa: Imprensa Nacional-Casa da Moeda, 1994. ( 2 volumes).

BARBOSA, Rui. Reforma do ensino primário e várias instituições complementares da Instrução Pública. Rio de Janeiro: Ministério da Educação e Saúde, 1946. (Obras Completas de Rui Barbosa, v. 10, Tomo II).

BORGES, Abilio Cesar. Desenho linear ou elementos de geometria prática popular. Rio de Janeiro: Typ. Aillaud, Alves \& Cia, 1882.

CARRAHER, Terezinha Nunes, CARRAHER, David William, SCHLIEMANN, Analúcia Dias. Na vida dez, na escola zero. São Paulo: Cortez Editora, 1988.

CHARTIER, Roger. A história cultural - entre práticas e representações. Lisboa: Editora Difel; Rio de Janeiro: Bertrand Brasil, 1990.

Les représentations du passé. Sciences humaines. Hors Série. Paris, n. 18. p. 13-18, sep./oct. 1997. 
Escuchar a los muertos com los ojos. Buenos Aires: Katz Editores, 2008.

CHERVEL, André. História das disciplinas escolares: reflexões sobre um campo de pesquisa. Teoria \& Educação, Porto Alegre, v. 2, p. 177-229, 1990

CLEMENTS, Douglas. Geometric and spatial thinking in young children. National Science Foundation. Arlington, VA. 1998. Disponível em: <http://www.eric.ed.gov/ERICWebPortal/ search/detailmini.jsp?_nfpb=true\&_\&ERICExtSearch_SearchValue_O=ED436232\&ERICExtS earch_SearchType_O=no\&accno=ED436232>. Acesso em: 05 maio 2013.

Concrete Manipulatives, Concrete Ideas. Contemporary Issues in Early Childhood. Oxford, UK: Editora Symposium Jounals, v. 1, n. 1, p. 45-60, 1999.

FAYOL, Michel. Fazer operações e resolver problemas - reflexões relativas ao ensino da aritmética. IN: FAYOL, Michel; TOOM, Andrei; BIVAR, Antonio; AIRES, Luis M. Fazer contas ajuda a pensar? Portugal: Porto Editora/Fundação Francisco Manuel dos Santos, 2010.

FREIRE, Olavo. Primeiras noções de geometria prática. Rio de Janeiro: Francisco Alves \& Cia, 1907.

LEME DA SILVA, Maria Célia. Novo programa de ensino, novos livros didáticos: mudanças didático-pedagógicas no conceito de número no Curso Primário (1949-1968). In: REUNIÃO ANUAL DA ANPEd, 34., 201 1, Natal. Anais eletrônicos... Natal: Anped; Universidade Federal do Rio Grande do Norte, 2011 . Disponível em: <http://34reuniao.anped.org.br/ images/trabalhos/GT19/GT19-153\%20int.pdf>. Acesso em: 31 jan. 2012.

LIBERMAN, Manhúcia Perelberg, FRANCHI, Anna, BECHARA, Lucilia. Curso moderno de matemática para a escola elementar. São Paulo: Companhia Editora Nacional, 1967. 11 volume).

Curso moderno de matemática para a escola elementar. São Paulo: companhia Editora Nacional, 1968. (3 volumes).

LIBERMAN, Manhúcia Perelberg, BECHARA, Lucilia. Curso moderno de matemática para a escola elementar. São Paulo: Companhia Editora Nacional, 1969. (4 volumes).

LIMA, Paulo Figueiredo; CARVAlHO, João Bosco Pitombeira Fernandes. Geometria. In: CARVALHO, João Bosco Pitombeira Fernandes (Coord.). Matemática: ensino fundamental. Brasília: Ministério da Educação, Secretaria de Educação Básica, 2010, p. 135-166.

MIGUEL, Antonio; VILELA, Denise. Práticas escolares de mobilização de cultura matemática. Caderno Cedes, Campinas, v. 28, n. 74, p. 97-120, jan./abr. 2008. 
MILANO, Miguel. Manual do ensino primário $-1^{\circ}$ ano. Rio de Janeiro, São Paulo, Belo Horizonte: Livraria Francisco Alves, 1938.

MORAIS, José. A aprendizagem dos sistemas simbólicos dos fonemas e das quantidades numéricas: semelhanças, diferenças e relações. In: CRATO, Nuno (Org.). Ensino de matemática: questões e soluções. Lisboa: Fundação Calouste Gulbenkian, 2011.

BRASIL. Secretaria de Educação Fundamental. Parâmetros Curriculares Nacionais: matemática. Secretaria de Educação Fundamental. Brasília: MEC/SEF, 1997.

POPKEWITZ, Tomaz. Políticas educativas e curriculares - abordagens sociológicas críticas. Portugal: Edições Pedago, 2011.

SOUZA, Alfredina de Paiva e. Nossa aritmética $3^{\circ}$ ano. Porto Alegre: Livraria do Globo, 1937.

TRAJANO, Antonio. Aritmética primária. 12. ed. Rio de Janeiro: Companhia Typographica do Brasil, [1 889 ou 1890].

VALENTE, Wagner Rodrigues (Org.). A educação matemática na escola de primeiras letras 1850-1960: um inventário de fontes. São Paulo: GHEMAT/FAPESP, 20 10. 1. DVD.

Tempos de Império: a trajetória da geometria como um saber escolar para o curso primário. Revista Brasileira de História da Educação, Campinas, v. 12, n. 30, p. 73-94, set./dez. 2012.

VALENTE, Wagner Rodrigues. Que geometria ensinar? Uma breve história da redefinição do conhecimento elementar matemático para crianças. Pro-Posições, Campinas, v. 24, n. 1, p. 159-178, jan./abr. 2013. (On-line).

VIDAL, Diana Gonçalves. Tecendo história (e recriando memória) da escola primária e da infância no Brasil: os grupos escolares em foco. In: VIDAL, Diana Gonçalves (Org.). Grupos escolares: cultura escolar primária e escolarização da infância no Brasil (1893-1971). Campinas: Mercado das Letras, 2006. 
Profa Dra. Maria Célia Leme da Silva Universidade Federal de São Paulo | Campus Diadema Setor de Física e Matemática Departamento de Ciências Exatas e da Terra Grupo de Pesquisa de História da Educação Matemática | GHEMAT E-mail | celia.leme@unifesp.br

Prof. Dr. Wagner Rodrigues Valente Universidade Federal de São Paulo | Campus Guarulhos Escola de Filosofia, Letras e Ciências Humanas Departamento de Educação Coordenador do Grupo de Pesquisa de História da Educação Matemática | GHEMAT Site | www.unifesp.br/centros/ghemat

Recebido 23 set. 2013 Aceito 05 dez. 2013 